\title{
Corticoterapia: manifestações oculares adversas
}

\author{
Corticotherapy: adverse eye manifestations
}

\author{
Corticoterapia: manifestaciones oculares adversas
}

Bianca Carollyne Martins Pinto ${ }^{1 *}$, Felippe Amaral Simões ${ }^{1}$, Gabriela Freitas Moreira ${ }^{1}$, Leonardo Mendonça Monteiro de Castro ${ }^{1}$, Luisa Pires Coscarelli ${ }^{1}$, Matheus Borges de Castro ${ }^{1}$, Emílio Rintaro Suzuki Junior².

\section{RESUMO}

Objetivo: Analisar as manifestações oculares adversas ao uso de corticosteróides na oftalmologia, apresentando indicações e vias de administração dessas drogas. Revisão bibliográfica: Os corticóides são hormônios endógenos, produzidos pelo córtex da adrenal e também podem ser obtidos de forma exógena pelas medicações. Nesse contexto, a corticoterapia é aplicada em uma gama de patologias, incluindo as oculares. Somando-se a isso, existem diversas vias de administração utilizadas na oftalmologia, como: comprimidos, injeções subconjuntivais, perioculares, intraoculares ou intravítreas e medicamentos tópicos. Apesar das vantagens da corticoterapia em tratamentos oftalmológicos, há possibilidade de ocorrência de efeitos adversos, muitas vezes graves e irreversíveis, relacionados ao uso, principalmente naqueles pacientes que fazem administração prolongada e/ou de doses elevadas. Em relação ao sistema ocular, os principais efeitos adversos são aumento da pressão intraocular, glaucoma, catarata e, raramente, endoftalmite e coriorretinite. Considerações finais: Esta revisão bibliográfica, portanto, tem como objetivo abordar o uso indispensável da corticoterapia e as ressalvas sobre o seu manejo cauteloso, com indicação e supervisão médica, baseado na clínica e no perfil do paciente.

Palavras-chave: Corticosteróides, Manifestações oculares, Efeitos adversos.

\begin{abstract}
Objective: Analyze the adverse eye manifestations using corticosteroids in ophthalmology, presenting the indications and the ways that these drugs can be administrated. Bibliographic review: Corticosteroids are endogenous hormones, produced by the adrenal cortex and can be obtained exogenously by medications. In this context, corticotherapy is applied in a range of pathologies, including ocular. In addition, there are several ways of administration used in ophthalmology, such as: tablets, subconjunctival, periocular, intraocular or intravitreal injections and topical medications. Despite the advantages of corticosteroid therapy in ophthalmic treatments, there is a possibility of adverse effects, often severe and irreversible, related to use, especially in those patients who are taking long-term and / or high doses. Regarding the ocular system, the main adverse effects are increased intraocular pressure, glaucoma, cataracts and, rarely, endophthalmitis and chorioretinitis. Final considerations: It is valid and, in some cases, indispensable, the use of corticotherapy, however, they should be performed cautiously, under medical indication and supervision, based on the clinic and the patient's profile.
\end{abstract}

Keywords: Corticosteroids, Eye manifestations, Adverse effects.

\section{RESUMEN}

Objetivo: Analizar las manifestaciones oculares adversas al uso de corticosteroides en oftalmología, presentando indicaciones y vías de administración de estos fármacos. Revisión bibliográfica: Los corticosteroides son hormonas endógenas, producidas por la corteza suprarrenal y se pueden obtener de manera exógena con medicamentos. En este contexto, la corticoterapia se aplica en una variedad de patologías, incluida la ocular. Además, existen varias vías de administración utilizadas en oftalmología, tales como: tabletas, inyecciones subconjuntivales, perioculares, intraoculares o intravítreas y medicamentos tópicos. A pesar de las ventajas de la terapia con corticosteroides en los tratamientos oftálmicos, existe la posibilidad de efectos adversos, a menudo graves e irreversibles, relacionados con el uso, especialmente en aquellos pacientes que están tomando dosis a largo plazo y / o altas. Con respecto al sistema ocular, los principales efectos adversos son aumento de la presión intraocular, glaucoma, cataratas y, en raras ocasiones, endoftalmitis y coriorretinitis. Consideraciones finales: Es válido y, en algunos casos, indispensable, el uso de corticoterapia, sin embargo, deben realizarse con precaución, bajo indicación y supervisión médica, según la clínica y el perfil del paciente.

Palabras clave: Corticoesteroides, Manifestaciones oculares, Efectos adversos.

${ }_{1}^{1}$ Pontifícia Universidade Católica de Minas Gerais (PUC-MG), Betim - MG. *E-mail: laofpucmg@gmail.com

${ }^{2}$ Centro Oftalmológico de Minas Gerais (COMG), Belo Horizonte - MG. 


\section{INTRODUÇÃO}

Os corticoides são hormônios esteroides produzidos, de forma endógena, pelo córtex da glândula adrenal e obtidos, de forma exógena, pelas medicações. São drogas amplamente utilizadas por desempenharem papéis diversos em quase todos os sistemas fisiológicos do corpo, incluindo efeitos antiinflamatórios e imunossupressores, inibição da formação de prostaglandinas, leucotrienos e supressão da produção de interleucina 2, entre outras citocinas.

Esses efeitos podem variar conforme a posologia e o tempo de uso; em geral, doses mais baixas conferem efeito antiinflamatório e mais altas, imunossupressor. A corticoterapia é aplicada em uma gama de patologias, como asma, alergias e doenças autoimunes, por diferentes especialidades da área da saúde. Por esse fator, os corticoides se enquadram como um dos grupos de drogas mais prescritos mundialmente, movimentando em torno de 10 bilhões de dólares por ano (FINAMOR LP, et al., 2002; RAMAMOORTHY S e CIDLOWSKI JA, 2016; ZEMANOVÁ M e MATUSKOVÁ V, 2017).

As vias de administração são diversas e sua escolha se baseia nas características da comorbidade apresentada e no perfil do paciente. Quando se deseja que eles atuem em nível ocular, deve-se ter em mente que existem duas barreiras anatômicas, tanto a hematoaquosa quanto a hematoretiniana, que limitam a difusão do medicamento. Na oftalmologia, as principais vias são: tópica, periocular, sistêmica e intraocular (FINAMOR LP, et al., 2002; HERNÁEZ-ORTEGA MC, 2003).

Apesar das vantagens da corticoterapia em tratamentos oftalmológicos, como em processos inflamatórios da córnea e na minimização de rejeição do enxerto na ceratoplastia, há possibilidade de ocorrência de efeitos adversos, muitas vezes graves e irreversíveis, relacionados ao uso, principalmente naqueles pacientes que fazem administração prolongada e/ou de doses elevadas.

Tais eventos podem ser sistêmicos, como aumento da glicemia, retenção de líquidos, acidose, hipocalemia, ou restritos a alguns sistemas do organismo. Aumento da pressão intraocular, glaucoma, catarata, endoftalmite e coriorretinite constituem os principais eventos adversos que acometem o sistema ocular (FUNG AT, et al., 2020; KADMIEL M, et al., 2016).

O controle de inflamações intraoculares que se encontram na fase aguda é extremamente necessário, como dito anteriormente, complicações podem prejudicar a visão até mesmo de forma irreversível. Nesse contexto, pode ser utilizada a estratégia "step-up" para o controle das inflamações. Ela se trata de uma terapia progressivamente introduzida, como primeira escolha, via tópica, até que atinja um bom controle da inflamação intraocular.

Entretanto, é a falha nesse tratamento que pode desencadear o surgimento de glaucoma ou catarata ou apenas ausência de resposta, sendo necessário outra forma de tratamento. Vale ressaltar, além dos corticosteróides tópicos outras formas são utilizadas na oftalmologia, como: comprimido ou injeções subconjuntivais, perioculares e intraoculares ou intravítreas (ROSSI C, et al., 2019; KACMAR J e CHOLEVIK $D, 2018)$. Diante desta situação é necessário cautela ao indicar a utilização dos corticosteróides, visto que, além de alterar o quadro clínico do paciente, a prescrição incorreta pode agravar o equilíbrio diagnósticoterapêutico e, frequentemente, prolongar ou piorar o tratamento.

Recomenda-se um monitoramento mais rigoroso dos recém-nascidos que recorrem a este medicamento; em geral, não devem ser utilizados quando o benefício não excede significativamente o risco de sua administração (ZEMANOVÁ M e MATUSKOVÁ V, 2017; JINAGAL J, et al., 2019). Este artigo tem como objetivo analisar as manifestações oculares adversas ao uso de corticosteróides na oftalmologia, apresentando indicações e vias de administração dessas drogas.

\section{REVISÃO BIBLIOGRÁFICA}

O olho é vulnerável a danos por níveis relativamente baixos de inflamação intraocular. As barreiras hematoaquosas e hematoretinianas geralmente limitam a penetração de proteínas e células da circulação periférica, no entanto, a presença de condições inflamatórias e/ou trauma cirúrgico induz alterações nessas barreiras resultando em sinais e sintomas clínicos clássicos de inflamação ocular, incluindo vermelhidão, dor, inchaço e coceira, os quais, se não tratados, podem levar a efeitos temporários ou perda permanente da visão (COMSTOCK T e DECORY H, 2012). 
Os corticóides são utilizados na oftalmologia principalmente para suprimir as condições inflamatórias e alérgicas, reduzir inflamações pós-traumáticas, retardar a cicatrização pela diminuição de fibroblastos e, mais recentemente, são testados em tratamentos contra a proliferação fibrovascular do pólo posterior.

Além disso, são usados, isoladamente ou em combinação com terapia antiangiogênica, para inibir a neovascularização ocular patológica que pode ocasionar a perda da visão se não tratada. A fim de otimizar a droga, minimizando os eventos adversos locais e sistêmicos, uma gama diversificada de gotas, pomadas e veículos tópicos de liberação retardada foram desenvolvidos nos últimos anos.

No entanto, apesar do desenvolvimento contínuo de técnicas e meios para a administração de corticosteróides, efeitos colaterais continuam sendo relatados (AWAN M, et al., 2009; GÓMEZ DP, et al., 2011; SULAIMAN R, et al., 2018).

\section{Indicações e vias de administração da corticoterapia}

A corticoterapia na oftalmologia é amplamente utilizada. Seu uso deve ser racional e bem indicado para se realizar um tratamento clínico eficaz e com menos efeitos colaterais. As diferentes respostas terapêuticas e reações adversas dos glicocorticóides sistêmicos dependem da regulação das suas principais ações antiproliferativa e antiinflamatória. Portanto, ao indicar a corticoterapia, deve-se basear principalmente, no tipo de glicocorticóide utilizado, sua via de administração e patologia.

A uveíte não infecciosa é um grupo heterogêneo de patologias inflamatórias, cuja evolução pode complicar em catarata, glaucoma e edema macular, que devido a esses possíveis danos irreparáveis, se torna uma das principais causas de cegueira em países desenvolvidos. O tratamento de primeira linha para conter o dano visual e a inflamação são os corticóides, administrados via tópica, periocular, intravítrea e sistêmica (oral ou endovenosa) e mais recentemente os implantes intravítreos (LEAL I, et al., 2016).

O Lúpus Eritematoso Sistêmico (LES) pode acometer a visão, especialmente, se houver concomitante uma Síndrome do Anticorpo Antifosfolípide, sendo caracterizada por vasculite (mais comum na doença ativa), retinopatia $(7,5 \%)$ e lesão trombótica da artéria e veia central retinianas $(13,9 \%)$ sendo acompanhado ou não de edema macular com descolamento da retina.

Como tais quadros cursam com vasculite, ao ser diagnosticado devemos na emergência fazer corticóide endovenoso, pulsoterapia com metilprednisolona e, geralmente, iniciar dose diária de corticóide oral. Quando não há respostas clínicas dessa terapêutica, edema macular ou inflamação crônica, se usa a via de depósito subtenoniano (acetato de triancinolona), pois possibilita maior absorção e reduz efeitos colaterais (HADLER BC e BORGES H, 2018).

Outra importante indicação dessas drogas é contra a rejeição ao transplante de córnea. Este é o tecido mais transplantado do país, segundo o Registro Brasileiro de Transplantes de janeiro a setembro de 2019 foram realizados $10.995,54 \%$ do total de transplantes do país.

Para inflamações de conjuntivas, pálpebras, córnea, conjuntivite alérgica, indica-se o uso de acetato de prednisolona a $1 \%$ pomada ou colírio. Caso haja intensa inflamação local ou alto risco de rejeição deve-se optar por vias de administração subconjuntivais ou intravenosas (MELO R, 2018; RANDLEMAN e STULTING, 2004).

A corticoterapia para toxoplasmose ocular não apresenta consenso sobre o seu uso e início. A terapia clássica é antibiótico com corticóide, principalmente prednisona via oral. Há serviços que iniciam apenas quando há acometimento do polo posterior, vitreíte intensa, lesões próximas ao disco óptico, ou ainda quando estão diante de pacientes imunossuprimidos; outros já iniciam junto com a antibioticoterapia ou um a três dias depois (LIMA GSC, 2017).

\section{Corticóide tópico}

O uso de corticóide tópico pode ser indicado de forma isolada ou, em casos graves e refratários, junto com a via sistêmica. Na oftalmologia, o uso tópico se dá por meio de colírios ou pomadas, preparados em soluções ou suspensões, permitindo melhor absorção na câmara anterior do olho e, assim, rápida ação antiinflamatória. Seus principais exemplares são os colírios de dexametasona, fluormetolona, betametasona, prednisolona e rimexolona (GÓMEZ DP, et al., 2011; ZEMANOVÁ M e MATUSKOVÁ V, 2017). 
Destacam-se como principais indicações desta via: uveítes, blefarite, esclerite, ceratites, hemangioma neonatal, conjuntivite alérgica, síndrome do olho seco grave, lesões mucocutâneas da conjuntiva, inflamações pós-operatórias e até transplantes de córnea. Para a terapia de qualquer um desses quadros, é recomendado que o início da terapia seja realizado de forma mais agressiva garantindo resolução mais rápida do quadro, e reduzindo a duração do tratamento e os efeitos colaterais. Além disso, é necessário o monitoramento periódico da PIO dos pacientes durante o uso e, logo após a melhora clínica, deve-se realizar o desmame do corticóide (FINAMOR LP, et al., 2002).

\section{Corticóide periocular}

Utilizado em dois meios - subconjuntival ou subtenoniana, sendo a primeira preparação mais rápida e de curta ação e a segunda de depósito e longa duração. A principal solução disponível para uso subconjuntival é a dexametasona e para uso subtenoniano o acetato de metilprednisolona e a triancinolona. Devido à erros técnicos, algumas complicações podem ser geradas como hemorragia subconjuntival, edema palpebral e atrofia óptica em consequência à lesão do nervo óptico. Esta via é contraindicada na esclerite e na conjuntivite, sendo também controversa na ceratite (FINAMOR LP, et al., 2002; GÓMEZ DP, et al., 2011).

O uso do corticóide periocular tem como principais indicações: uveíte anterior aguda severa em portadores de Espondilite Anquilosante, uveítes anteriores crônicas resistentes, nas quais é utilizado juntamente de corticóides sistêmicos, pós-operatórios de cirurgia de catarata, transplante de córnea e retina, uveítes intermediárias e vasculites retinianas, reação inflamatória vítrea associada com a síndrome de recuperação imunológica em pacientes com AIDS, em pacientes com baixa adesão ao tratamento tópico ou sistêmico e má adesão ao tratamento ou contraindicações às drogas sistêmicas. É recomendado monitorar a PIO devido ao maior risco de glaucoma corticogênico, principalmente nas preparações de depósito de longa duração (FINAMOR LP, et al., 2002).

\section{Corticóide sistêmico}

Esta é uma terapia que necessita de cautela e controle ao ser administrada. Inicialmente, deve-se excluir infecções, calcular a pressão intraocular (PIO) e acompanhá-la. Está associada com a formulação tópica e a primeira escolha é a prednisona de $1 \mathrm{a} 1,5 \mathrm{mg} / \mathrm{kg} / \mathrm{dia}$, em dose única pela manhã (SULAIMAN R, et al., 2018; ZEMANOVÁ M e MATUSKOVÁ V, 2017).

Podem ser listadas como principais indicações dessa modalidade de terapia: uveíte tuberculosa, oftalmia simpática, sarcoidose, espondilite anquilosante, Síndrome de Behçet, vasculites idiopáticas, toxoplasmose, conjuntivite herpética, oftalmopatia associada à tireoide, rejeições graves de enxerto da córnea, traumas oculares e pseudotumor orbital. É recomendado iniciar uma redução lenta da dosagem inicialmente estabelecida, monitorando cuidadosamente os pacientes em relação aos efeitos adversos da medicação a longo prazo e utilizar a pulsoterapia em alguns casos de uveíte autoimune, especialmente em pacientes com doença ocular grave bilateral e com risco de perda visual rápida, como neurite óptica. Em geral o tratamento é feito com metilprednisolona $500 \mathrm{mg}-1 \mathrm{~g} / \mathrm{dia}$, durante três dias (FINAMOR LP, et al., 2002).

\section{Corticóide intra-ocular}

Os corticóides administrados por via sistêmica ou tópica, normalmente não atingem concentrações terapêuticas na retina, pois devem primeiro atravessar a barreira hematorretiniana. Assim, um meio alternativo para atingir concentrações terapêuticas no segmento posterior é a aplicação intravítrea (NENTWICH MM e ULBIG MW, 2012).

Um dos usos recentes de corticoterapia é a aplicação na forma de implantes intraoculares de depósito (de longa duração), como a Dexametasona ou injeções intravítreas de Triancinolona. Esses implantes foram desenvolvidos para prolongar o efeito de drogas intravítreas e diminuir a necessidade de aplicação repetida. Sua principal ação é reduzir a inflamação no pós-operatório e são indicados no tratamento de edema macular cistoide, na uveíte posterior crônica e em processos vasculares proliferativos do vítreo e da retina. Ademais, os principais efeitos adversos dos corticosteróides intravítreos incluem a indução ou piora da catarata e PIO elevada, sendo que a probabilidade de uma complicação varia de implante para implante e depende da duração da ação daquele em particular usado (FINAMOR LP, et al., 2002; GÓMEZ DP, et al., 2011; NENTWICH MM e ULBIG MW, 2012; SULAIMAN R, et al., 2018). 


\section{Reações adversas da corticoterapia}

As reações adversas sistêmicas geradas pela corticoterapia estão intimamente relacionadas ao bloqueio do eixo hipotálamo-hipófise-adrenal produzindo uma insuficiência adrenal aguda ou efeitos tóxicos devido a doses suprafisiológicas, como doenças digestivas (gastroduodenite), musculoesqueléticas (osteoporose), dérmicas (acne, púrpura), cardiovasculares (hipertensão, arritmias), psiquiátricas (irritabilidade, alterações mentais), metabólicas (estado cushingoide, função gonadal prejudicada, aumento do apetite, desequilíbrio eletrolítico), além de resultar em uma maior predisposição a infecções bacterianas, fúngicas e virais (GÓMEZ DP, et al., 2011).

Em pediatria, o uso de corticóides tópicos, podem levar a repercussões sistêmicas. Por possuir córneas mais finas e permeáveis, a criança tem uma rápida e intensa absorção ocular da medicação, por conseguinte é comum pacientes com sintomas característicos de Síndrome de Cushing e glaucoma corticogênico.

O Instituto de Pós-Graduação em Educação e Pesquisa Médica, Chandigarh, Índia; apresentou um relato de caso que ilustra a toxicidade do corticóide tópico em crianças. O lactente de 6 meses, diagnosticado com catarata congênita bilateral precisou usar, por 6 semanas, betametasona tópica 0,1\% 8x/dia, primeiramente devido ao pós-operatório de uma facoaspiração com capsulotomia, e posterior, com aumento da dosagem para ambos os olhos, devido à retirada de uma membrana na área pupilar, originada pelo uso tópico de corticosteróides. Após 6-8 semanas, intercorreu com ganho de peso, obesidade central e em tronco, e face de "lua cheia", quadro característico de Síndrome de Cushing por uso exógeno de corticosteróides (JINAGAL J, et al., 2019; ZEMANOVÁ M e MATUSKOVÁ V, 2017).

O glaucoma corticogênico acomete $18 \%$ a $36 \%$ dos pacientes oftalmológicos. Este é definido como neuropatia óptica desencadeada pela drenagem defeituosa do humor aquoso pela malha trabecular, resultando em acúmulo de glicosaminoglicanos em tal região, e aumento da resistência a saída deste líquido. Por isso, há um consequente aumento da PIO e compressão dos elementos do nervo óptico, gerando aumento da escavação, defeito no campo visual e, então, glaucoma de ângulo aberto.

Além da via de administração, o glaucoma corticotrófico tem relação com a concentração, dosagem, tipo de medicamento e predisposição genética do indivíduo, sendo que muitos são sensíveis a ele, mas poucos desenvolvem o glaucoma.

Fluormetolona, rimexolona ou medrisona têm menos tendência à aumento da pressão intraocular do que prednisona ou dexametasona. Seus principais fatores de risco são idade (os dois extremos da vida), diabetes, miopia e histórico familiar de glaucoma (CAPACIA RBS e FERRAZ RRN, 2018; JINAGAL J, et al., 2019; LIESENBORGHS I, et al., 2020).

A catarata é um importante efeito adverso da corticoterapia. Alguns fatores estudados relacionam sua ocorrência com a forma de administração, dose diária, dose cumulativa, duração do tratamento, idade e etnia do paciente. Somando-se a isso, o tempo mínimo para o aparecimento das complicações é de aproximadamente 1 ano de uso da medicação com doses iguais ou superiores a $10 \mathrm{mg} /$ dia de corticóide (prednisona é um exemplo).

Após o início de tratamento com corticoide oral e o tempo necessário para o surgimento das complicações, foi relatado em variados ensaios clínicos randomizados que a incidência de catarata varia entre 6,4\% e 38,7\%. Diante do diagnóstico, deve-se suspender a corticoterapia; se estágio inicial, pode haver resolução do quadro, entretanto em alguns pacientes, mesmo após a retirada da droga, a doença progride.

Em relação ao uso de glicocorticóides, a dexametasona influencia na proliferação e alongamento das células induzidas por FGF2, assim como na capacidade das células de se espalharem e cobrirem a cápsula posterior, resultando em catarata (CARDOZO PAL, et al., 2011; GURBAXANI A, et al., 2013; WANG C, et al., 2013).

A administração intraocular de corticosteroides pode ter como uma forma de complicação a endoftalmite bacteriana, decorrente da entrada de um microrganismo exógeno durante ou logo após o procedimento, que se prolifera causando reação inflamatória. A clínica, em geral, inicia com reação inflamatória leve a moderada, que possui como maior característica dor, reação intraocular e formação de fibrina. A endoftalmite não infecciosa se enquadra como evento adverso com prevalência que varia de $0,5 \%$ a $2,0 \%$ ao uso de corticosteroides. 
Essa patologia se caracteriza por uma reação inflamatória transitória que, de forma geral, apresenta-se com hipópio e manifesta após dois a três dias da injeção intravítrea de acetato triancinolona. Em sua maioria, é ausente ou mínima a inflamação da esclera e da conjuntiva; dor e fibrina na câmara anterior são encontrados em raros casos. Tal quadro habitualmente é autolimitado, com resolução em uma a duas semanas, no entanto há um número pequeno de situações em que há opacificação vítrea persistente (FUNG AT, et al., 2020; ROTH DB e JUNIOR HWF, 2008). Apesar de ser uma condição rara, a endoftalmite continua sendo um efeito adverso devastador em pacientes que recebem injeções intravítreas. Em um estudo utilizando injeções de corticoide e de bactérias em coelhos, foi constatado que os olhos que recebiam injeções de corticoides necessitavam de uma carga de bactérias menor para desenvolver endoftalmite em comparação ao grupo controle (VANDERBEEK BL, et al., 2015).

A coriorretinite serosa central, complicação menos reconhecida do uso do corticosteróide, pode ocorrer pelo uso de esteróides tópicos, orais ou inalatórios. Os pacientes apresentam escotoma central com redução variável da acuidade visual, frequentemente associada a discromatopsia, micropsia e sensibilidade ao contraste reduzida. Além disso, o paciente pode queixar embaçamento da visão resultante de uma mudança na refração, a hipermetropia. Ainda é obscuro o motivo desencadeante desses fatos, porém acredita-se que seja relacionado a permeabilidade alterada da vasculatura coróide e/ou disfunção focal do epitélio da retina, eventos que, mesmo, autolimitados, podem provocar danos permanentes (GURBAXANI A, et al., 2013).

O manejo deve ser cauteloso e bem monitorado, preferindo terapias com baixas dosagens e medindo a PIO prévia ao tratamento, para dar seguimento de acordo com a proposta terapêutica. Em pacientes com terapia tópica, a PIO deve ser reavaliada em 2 semanas após início do tratamento, depois em 4 semanas e a cada 2 a 3 meses posteriormente. Já pacientes portadores de doenças como LES, que necessitam de corticoterapia crônica deve acompanhar a PIO no primeiro mês, depois após 3 meses e, por fim, a cada 6 meses. Caso a PIO aumente muito com o uso do corticóide tópico ou sistêmico, deve-se retirá-lo ou substituílo por outra formulação, como Fluormetolona, se não puder suspender a terapia, pode-se adicionar um colírio betabloqueador como o Maleato de Timolol (LIAÑO LP, et al., 2012).

Para a retirada dos glicocorticóides $(G C)$ deve-se atentar à possibilidade de que o eixo hipotálamohipófiseadrenal esteja suprimido. Dessa forma, é aceitável uma retirada abrupta do GC quando é feito seu uso por até 7 dias, independente da dose, pois nessas condições o eixo tem condições de se recuperar. Nesse contexto, propõe-se uma retirada mais rápida quando está bem acima da dose fisiológica e assim, quando se encontra na faixa de dose fisiológica, gradua-se a retirada proporcionando às glândulas supra-renais uma estimulação progressiva por ACTH endógeno e a recuperação de seu trofismo e capacidade de produção de esteróide. Ressalta-se que a retirada do GC pode desencadear um quadro sindrômico (síndrome da retirada do glicocorticoide) que requer atenção (DAMIANI D, et al., 2001).

Não há um consenso proposto de retirada, com exceção da terapia aguda (7-14 dias), em que não há supressão do eixo HHA, e, assim, a retirada abrupta é recomendada. Os protocolos fazem uma retirada gradual, cujo objetivo inicial é reduzir para dose fisiológica. Antes de iniciar a retirada deve se realizar exames para monitorar a doença base e ficar atento a reagudização, caso não tenha doença base, a redução para posologia fisiológica será mais rápida (ALVES C, et al., 2008).

(ALVES C, et al., 2008) propõe no seu serviço reduzir 20\% (se doença base, reduzir $10 \%$ ) da dose a cada 2-4 dias até atingir a dose fisiológica, em seguida, diminuir para metade da dose fisiológica, em 2-4 semanas. Ao atingir a metade da dose fisiológica (5-6 mg/m²/dia hidrocortisona ou 5-6 mg/ $/ \mathrm{m}^{2} /$ dia de prednisona) dosar o cortisol sérico matinal e ACTH mensalmente até atingir valores normais. Esta redução pode ser por meio da dose apenas uma vez ao dia (matinal) e depois passar a administrar em dias alternados ao longo da semana.

\section{Interações medicamentosas}

Os corticóides possuem ação tanto endócrina (glicocorticóide) quanto metabólica (mineralocorticóide). Em virtude disso, apresentam também repercussões na reabsorção renal dos eletrólitos, metabolismo de glicose e consequente impacto no controle glicêmico e na pressão arterial. Portanto, ao introduzir uma corticoterapia deve-se estar atento às interações medicamentosas decorrentes do uso concomitante dos esteróides com fármacos de uso controlado ou agudo do paciente (GÓMEZ DP, et al., 2011). 
Suas ações principais são antagonizar os efeitos hipogicêmicos dos antidiabéticos e os efeitos antihipertensivos dos bloqueadores alfa e beta; são antagonistas dos receptores da angiotensina II e reduzem a eficácia das drogas anticálcicas. Com o cetoconazol, a ação do corticosteróide integra-se a mais um resultado, gerando um aumento das propriedades imunossupressoras de ambos os medicamentos. Carbamazepina, barbitúricos e rifampicina diminuem as ações dos corticosteróides. O risco de sangramento gastroduodenal intensifica-se com o uso simultâneo de agentes antiinflamatórios não esteroidais. Os contraceptivos orais elevam as concentrações de esteroides no plasma (GÓMEZ DP, et al., 2011).

\section{CONSIDERAÇÕES FINAIS}

Os corticosteróides são hormônios de significativa importância fisiológica no corpo humano. Por possuírem, entre outros papéis, efeitos antiinflamatórios e imunossupressores, eles são capazes de controlar a exacerbação de patologias diversas. Entretanto, é notável que o uso de forma indiscriminada, na oftalmologia, por exemplo, pode propiciar o surgimento de eventos adversos, como catarata, coriorretinite, glaucoma, aumento da pressão intraocular e endoftalmite, além de reações medicamentosas a drogas em uso concomitante. Dessa forma, em alguns casos específicos é indispensável, o uso da corticoterapia, porém, devem ser realizadas de forma cautelosa, sob indicação e supervisão médica, baseado na clínica e no perfil do paciente.

\section{REFERÊNCIAS}

1. ALVES C, et al. Withdrawal from glucocorticosteroid therapy: clinical practice recommendations. Jornal de Pediatria, 2008; 84(3): 192-202.

2. AWAN M, et al. Penetration of topical and subconjunctival corticosteroids into human aqueous humor and its therapeutic significance. British Journal of Ophthalmology, 2009; 93: 708.

3. CAPACIA RBS, FERRAZ RRN. Vias de administração de corticosteróides e sua relação com o desenvolvimento de glaucoma cortisônico: síntese de evidências. Revista UNILUS Ensino e Pesquisa, 2018; 15(41).

4. COMSTOCK T, DeCORY H. Advances in corticosteroid therapy for ocular inflammation: Loteprednol Etabonate. International Journal of Inflammation, 2012.

5. DAMIANI D, et al., Corticoterapia e suas repercussões: a relação custo-benefício. Pediatria (São Paulo) 2001;(1):7182

6. FINAMOR LP, et al. Corticoterapia e Uveítes. Arquivos Brasileiros de Oftalmologia, 2002; 65: 483-6

7. FUNG AT, et al. Local delivery of corticosteroids in clinical ophthalmology: A review. Clinical \& Experimental Ophthalmology, 2020; 48: 366-401.

8. GÓMEZ DP, et al. Enfoque actual del empleo de corticosteroides en la terapéutica ocular. Medisur, 2011; 9(4): 360366.

9. GURBAXANI A, et al. Ocular complications associated with systemic medications used in allergy/immunology practice. Springer Science and Business Media New York, 2013; 13: 329-335.

10. HADLER BCM, BORGES H. Retinopatia vaso-oclusiva por lúpus eritematoso sistêmico associado à síndrome do anticorpo antifosfolipídeo. Revista Brasileira de Oftalmologia, 2018; 77(1): 50-53.

11. HERNAEZZ-ORTEGA, MC. Corticosteroides intraoculares. Archivos de la Sociedad Española de Oftalmologia, 2003; 78: 523-524.

12. JINAGAL J, et al. Systemic toxicity of topical corticosteroids. Indian Journal of Ophthalmology, 2019; 67(4): 559-561.

13. KACMAR J, CHOVELIK D. Corticosteroid induced posterior subcapsular cataract. Czech and Slovak Ophthalmology, 2018; 74(6): 226-236.

14. KADMIEL M, et al. Glucocorticoid action in human corneal epithelial cells establishes roles for corticosteroids in wound healing and barrier function of the eye. Experimental Eye Research, 2016; 152: 10-33.

15. LEAL I, et al. Análise da Revisão Cochrane: Implantes Corticosteróides para Uveíte Não Infecciosa Crônica. Cochrane Database Syst Rev, 2016; 2.

16. LIESENBORGHS I, et al. The Molecular Processes in the Trabecular Meshwork After Exposure to Corticosteroids and in Corticosteroid-Induced Ocular Hypertension. Investigative Ophthalmology \& Visual Science, 2020; 61(4).

17. LIMA GSC. Tratamento da Toxoplasmose Ocular Adquirida: Revisão Sistemática. Dissertação (Mestrado em Medicina) - Universidade Federal do Espírito Santo, Vitória, 2017; 43 p.

18. MELO MSB, RIBEIRO MA. Dor Ocular no Pós-operatório de Transplante de Córnea. Id on Line Revista Multidisciplinar e de Psicologia, 2018; 12(42): 548-560.

19. NENTWICH MM, ULBIG MW. The Therapeutic Potential of Intraocular Depot Steroid Systems. Department of Ophthalmology, Ludwig-Maximilians-University Munich: Prof. Dr. med. Ulbig, Dr. med. Nentwich, 2012.

20. RAMAMOORTHY S, CIDLOWSKI JA. Corticosteroids-Mechanisms of Action in Health and Disease. Rheumatic Diseases Clinics of North America, 2016; 42(1): 15-31.

21. ROSSI C, et al. Treatment of chronic non-infectious uveitis and scleritis. Swiss Medical Weekly, 2019.

22. ROTH DB, JUNIOR HWF. Distinguishing Between Infectious and Noninfectious Endophthalmitis After Intravitreal Triamcinolone Injection. American Journal Of Ophthalmology . 2008; 146(3): 346-347.e1.

23. SULAIMAN R, et al. Glucocorticoid receptor signaling in the eye. Steroids, 2018; 133: 60-66.

24. VANDERBEEK BL, et al. The Association between Intravitreal Steroids and Post-Injection Endophthalmitis Rates. American Academy of Ophthalmology. 2015. 122(11): 2311-2315.e1.

25. WANG C, et al. Dexamethasone Influences FGF-induced Responses in Lens Epithelial Explants and Promotes the Posterior Capsule Coverage That Is a Feature of Glucocorticoid-Induced Cataract. National institutes of health, 2013.

26. ZEMANOVÁ M, MATUSKOVÁ V. Benefits and negatives of corticosteroid therapy in corneal patients. Czech and Slovak Ophthalmology, 2017; 73(2): 69-77. 